\title{
DEFORMATION MONITORING IN AND AROUND THE NATIONAL CAPITAL REGION OF INDIA USING DINSAR TECHNIQUE
}

\author{
Monika $^{1,}{ }^{*}$, H. Govil ${ }^{1}$, Claudia Meisina ${ }^{2}$, P. Diwan ${ }^{1}$, Mahesh Kumar Tripathi ${ }^{1}$, Subhanil Guha ${ }^{1}$ Neetu Gill ${ }^{3}$, \\ ${ }^{1}$ Department of Applied Geology, National Institute of Technology, Raipur, India - geniousmonika11@gmail.com \\ ${ }^{2}$ Dipartimento di Scienze della Terra e dell'Ambiente, Università degli Studi di Pavia, Pavia \\ ${ }^{3}$ Chhattisgarh Council of Science \& Technology, Raipur, India
}

Commission V, SS: Disaster Monitoring, Damage Assessment and Risk Reduction

KEY WORDS: Sentinel-1, DInSAR, Deformation, NCR, Vasundra

\begin{abstract}
Urbanization increases the pressure on land and ground water. Due to pressure on land and over extraction of the ground water for modernization and development, deformation of land increase. The traditional deformation monitoring techniques are costly and time taking. The Differential Interferometry Technique (DInSAR) has capability to monitor regional scale deformation. Recently Vasundra region of the NCR has experienced a road subsidence near to the multiple stories building. In the study we have attempted to identify the Vasundra and nearby region by the DInSAR technology to identify the deformation in Delhi and NCR focused on the Vasundra area of Ghaziabad, Uttar Pradesh, India. This is one of the developed and planned area in the Ghaziabad District. The Sentinel-1 C data has been used to monitor the deformation in that area. The Vasundra area has been deformed due to heavy rainfall and water logging in the surrounding area by which the road has been subsided up to 30 feet. Using the sentinel data we were able to identify the subsidence in Vasundra and nearby areas. Since the Sentinel scene was very big so a clear picture of the deformation indication in the NCR region are found which need more in-depth study further. Conclusively it can be said that DInSAR technique with Microwave data is a competent tool to monitor the minute deformation.
\end{abstract}

\section{INTRODUCTION}

This research focuses on space borne SAR imagery for monitoring surface deformation in urban area. The technology is fast improving with enhanced synthetic aperture radar (SAR) sensors on different space born (Jiang et al. 2011) platforms, providing high-resolution imagery at any atmospheric conditions, day-night capturing capability and covers large area (Tomiyasu 1978)(Geymen 2014)(Ng et al. 2011). SAR interferometry concept has been introduced in the last 1980 (Gabriel, Goldstein, and Zebker 1989). Interferometry SAR (InSAR) (Aydoner, Maktav, and Alparslan 2004) techniques are widely used to measure the topographic profile (Bürgman, Rosen, and Fielding 2000) and surface deformations (Ishwar and Kumar 2017)(Fulton 2000)(Burgmann, Rosen, and Fielding 2000; Bürgmann, Rosen, and Fielding 2000; Iglesias et al. 2015; Klees and Massonnet 1999; Otir and Komac 2007; Peltier et al. 2010; Qiu et al. 2016; Samieie-Esfahany et al. 2009) and subsidence monitoring (Strozzi et al. 2001). Differential SAR-Interferometry (D-InSAR) is one of the competent technique use to identify the land surface horizontal motion and land subsidence (Ishwar and Kumar 2017)(Strozzi et al. 2001)(Bhattarai et al. 2017; Caló et al. 2017; Champati, Head, and Studies 2001; Chang, Ge, and Rizos 2005) over a large area at low cost than the traditional techniques $(\mathrm{Ng}$ et al. 2011) (Ferretti, Prati, and Rocca 2001).The precise leveling, total station and global navigation satellite system (GNSS) are common ground-based traditional measurement techniques which are used to monitor the subsidence at a pin point location in an area. Though these methods are timeconsuming, require more man power and costly, they can measure height information at millimeter to centimeter levels of accuracy on local area level (Cao et al. 2007). Typically deformation occurs due to resource extraction (States 1991)(Sahu and Lokhande 2015) and less buoyancy to support the external pressure, it occurs at low rates ranging from fraction to as much as 3 inch per year. (Fulton 2000) Subsidence is a certain effect of underground mining (Singh 1992). In the mining subsidence affected surface area is generally larger than the extraction area. The subsidence not only impact on the human also impact their environment (Sahu and Lokhande 2015) due to release of toxic gases (Jiang et al. 2011).

\section{STUDY AREA}

The total processed area shown in figure 1 is covered under $28^{\circ} 59^{\prime} 22^{\prime \prime} \mathrm{N}, 76^{\circ} 50^{\prime} 30^{\prime \prime} \mathrm{E}, 27^{\circ} 59^{\prime} 31^{\prime \prime} \mathrm{N}$ and $77^{\circ} 39^{\prime} 54^{\prime \prime} \mathrm{E}$. The area under investigation covered under $28^{\circ} 14^{\prime} 37^{\prime \prime} \mathrm{N}$, $76^{\circ} 59^{\prime 2} 27^{\prime \prime}$ E, 28 $8^{\circ} 53^{\prime} 14^{\prime \prime} \mathrm{N}$ and $77^{\circ} 31^{\prime} 37^{\prime \prime}$ E. The study area corresponds to the eastern part of Delhi and National capital region (NCR) of India. The study area includes major developing cities of Delhi and NCR since 1980s such as Noida, Faridabad Guru Gram and Ghaziabad (Figure 3). The major focus of this study has been on urban areas of NCR region of India which has been urbanized years back. Vasundra, Ghaziabad, India has been chosen for validation and ground data collection for deformation Vasundra is a township area since 1990s and well planned and developed.

\footnotetext{
* Corresponding author
} 


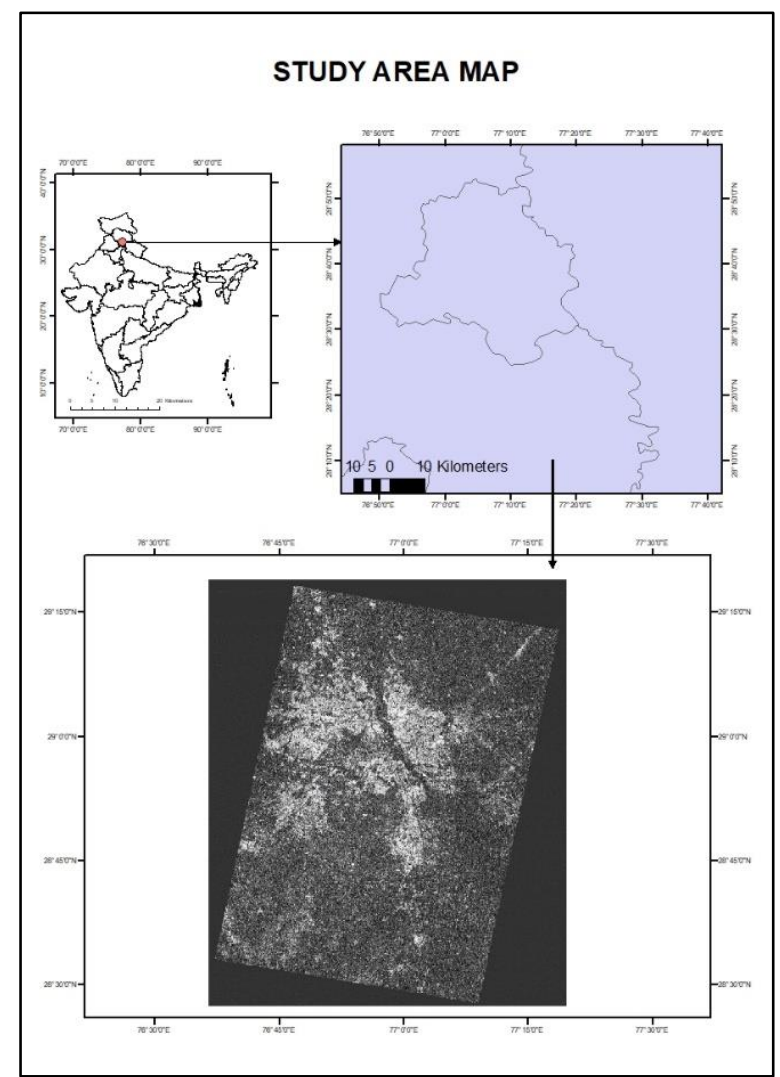

Figure 1 Study area map of Delhi and NCR region of India

It was shaped by Uttar Pradesh Housing and Development Authority in the late 1990s. The area map has been showing in figure 1. The area which has been chosen for surface deformation under investigation has been estimated approximate 3,000 sq.km form 6,378 sq.km total processed area (figure 3). In the area, Yamuna and Hindan River flow in the north east part of the area which is under investigation. The Vasundra area situated between both the river and near to Hindan River.

\section{DATA USE AND METHODOLOGY}

The two sceans of the C-band, data product of single look complex (SLC) were obtained through the European Space Agenacy (ESA) satellite Sentinel-1 (wavelength of 5.6 and temporal resolution is 12 days and spatial resolution $5 \times 20 \mathrm{~m}$ ) (Bourbigot et al. n.d.), from14 July 2018 to 26 July 2018. The SAR TOPS (terrain observation with scanSAR ) mode processing has been done on interferometric wide (IW) subswath1. The data detailed specification are given below in table. 1 .

\begin{tabular}{|l|l|l|l|l|}
\hline $\begin{array}{l}\text { Data } \\
\text { Acquisition }\end{array}$ & $\begin{array}{l}\text { Orb } \\
\text { it }\end{array}$ & $\begin{array}{l}\text { Perpendicu } \\
\text { lar Baseline }\end{array}$ & $\begin{array}{l}\text { Temporal } \\
\text { Baseline }\end{array}$ & $\begin{array}{l}\text { Cohre } \\
\text { nce }\end{array}$ \\
\hline $\begin{array}{l}26 / 07 / 18 \\
\text { (Master) }\end{array}$ & $\begin{array}{l}229 \\
58\end{array}$ & 0 & 0 & 0 \\
\hline $\begin{array}{l}14 / 07 / 18 \\
\text { (Slave) }\end{array}$ & $\begin{array}{l}227 \\
83\end{array}$ & 24.87 & 12 days & 0.97 \\
\hline
\end{tabular}

Table 1 Specification of data used for deformation in NCR, India
The methodology adopted in present study is shown in figure 2. The methodology consists in different steps: a) selection of suitable data pair which is a key step for any SAR processing; b) application of orbit file for precise position and velocity of the satellite at the time of acquiring; c) Coregistration of the images with the orbit and a Shuttle Radar Topography Mission(SRTM) digital elevation model (DEM) of 3 arc secound of same subswath with same polarisation (VV or $\mathrm{VH}$ ) of the product. d) resampling the slave image into master frame and, equalization, and calibration, e) Interferogram formation of two image by

\begin{tabular}{|c|}
\hline SLC Pair \\
\hline Apply Orbit File \\
\hline Coregistration \\
\hline \multicolumn{2}{|c|}{ y } \\
\hline Coherence And Interferogram Generation \\
\hline Phase Removal \\
\hline Filtering \\
\hline Geometric Correction \\
\hline Visualization And Interpretation \\
\hline
\end{tabular}

Figure 2 Methodology flow chart

complex congugate of (orbital data processing, interferogram calculation, interferogram flattening, called phase flattening which is corrupted by noise from temporal decorelation, geometric decorelation volumetric scattteing and processing errors, etc.) (Ferretti, Prati, and Rocca n.d.) of SLC data. The output images such as intensity, phase and cohrence has been examined for interpretation of the deformation in Delhi and NCR region. Terrain correction has been processed for compensate the distortion so that the geometeric representaion of image should be reperesented as close as posible to real world. The identification and interpretation has been done on google earth by analysing and comparing the resulted data with the real world imagenary. 


\section{RESULTS AND DISCUSSION}

The results described aim to monitor the surface deformation in the urban and developed region of NCR of India by focusing on Vasundra, Ghaziabad (pin point), India using Cband data of Sentinel-1 displayed in figure 3.

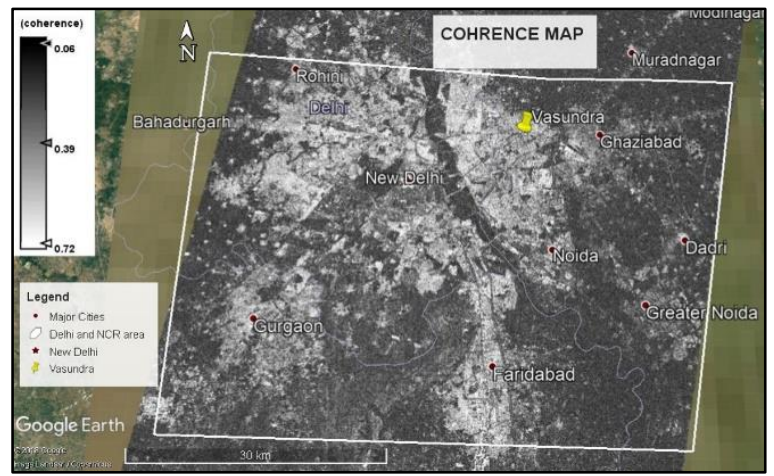

Figure 3 coherence image of NCR overlapped on google earth image to show major cities in rectangle and pin point area is Vasundra.

The products derived with the help of the data pair IW SLC Sentinel-1 images, spanning the period from $14^{\text {th }}$ July 2018 to $26^{\text {th }}$ July 2018 for surface deformation map. In figure 4 the total area covered derived coherence image with both the polarization with a time interval of 12 days. The VV polarized coherence show good results in the city areas then $\mathrm{VH}$ polarized coherence image. In VV coherence image bridges on the river are also easily distinguish which shows good coherence due to volume scattering. In resulted images of coherence showing that coherence varies from low to high with range from 0.6 to 0.79 . The values near to 0.6 are showing the low coherence due to presence of water body, vegetation, etc. and a good coherence has been observed near to 0.79 (high coherence due to less temporal resolution) which have good back scatting features such as buildings, bridges, etc. In the residential and industrial areas of Faridabad, Noida, Ghaziabad, Guru Gram and Delhi observed good coherence due to presence of building which have the prominent source of volume and double bounce scattering. In very low coherence, fringes have not been formed very clear due to heavy rain in the area. Where less or low coherence it has been observed due to water lodging in the area.

The consequent SAR interferometry images shown in figure 5 describe the fringes has been formed by the both VV and $\mathrm{VH}$ polarization. The location of deformation can be clearly identified but the high phase gradient over a large spatial extent made the phase fringes distinguishable. The fringes are closely to each other can be clearly identified more deformation (in square) in figure 6. The image having good coherence in urban area due to presence of building, increase double bounce scattering which has high reflectivity with a time interval of 12 days. The results show deformation in Delhi and NCR region but Delhi shows less deformation as compare to the NCR. The enclosed area in rectangle in figure

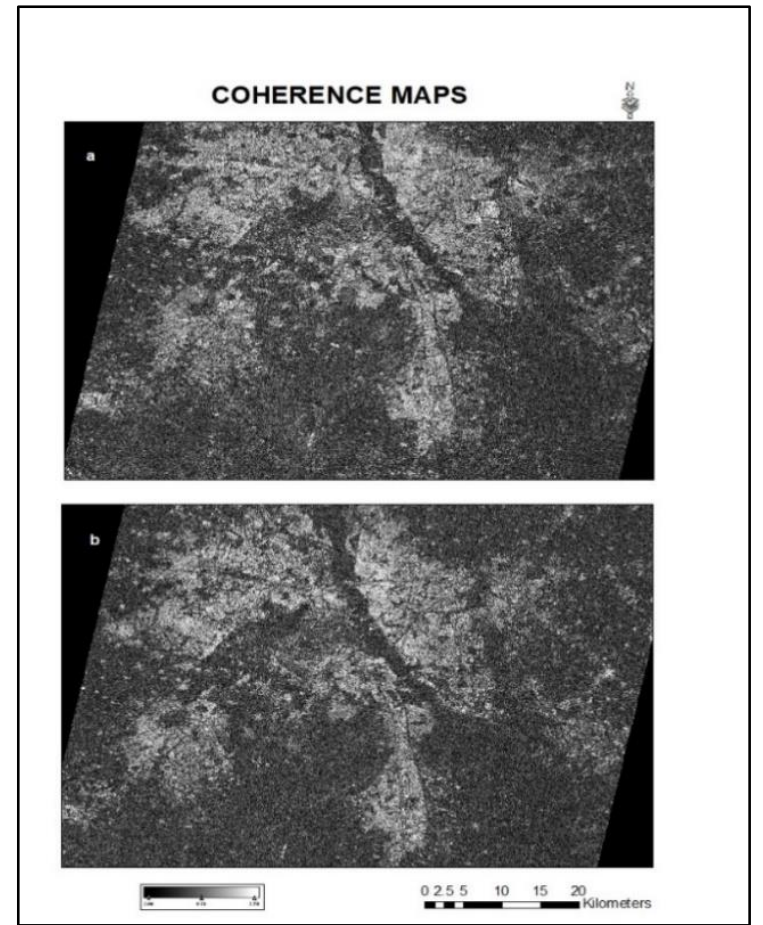

Figure 4 Coherence image generated from two images of NCR area of India, with a time interval of 12 days by (a) VV polarization and (b) VH polarization

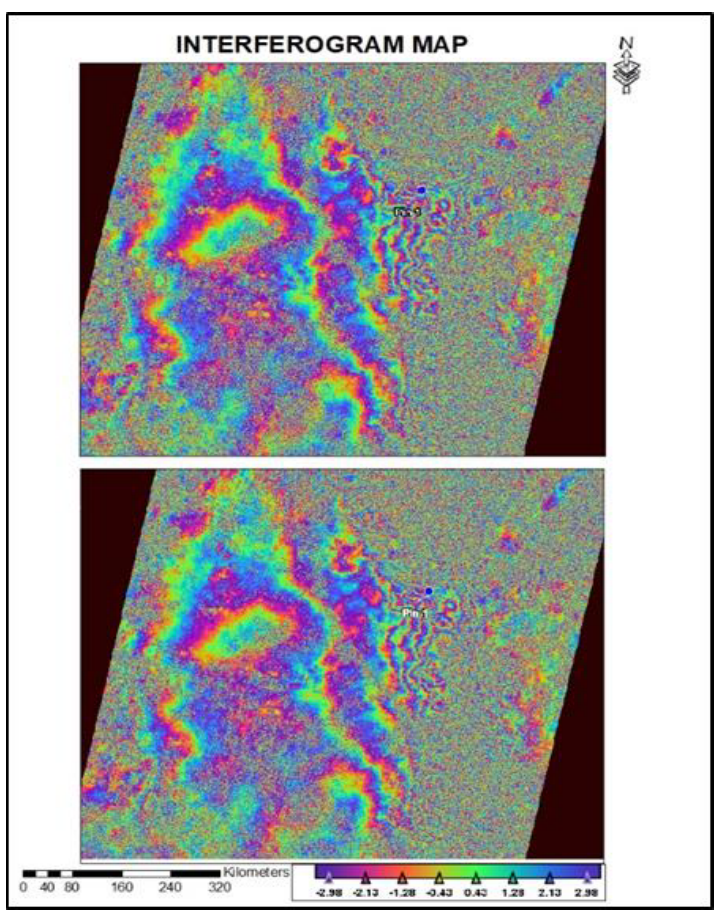

Figure 5 interferogram S-1 SAR interferometry. Fringes generated from two images of the NCR area of India, with a time interval of 12 days by VV polarization (upper) and VH polarization 


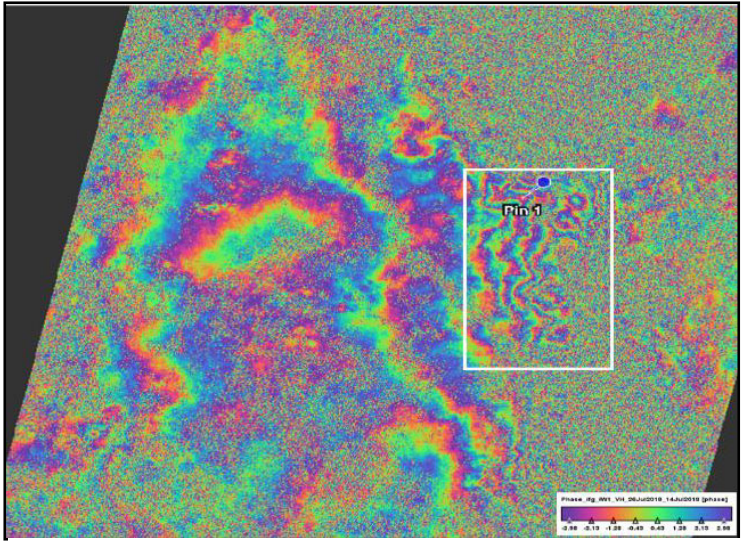

Figure 6 Interferogram fringes showing high deformation in enclosed rectangle

6 shows more deformation than the other area of Delhi and NCR as the fringes in the NCR are more close to each other (Figure 7) due to rain fall and water logging in the area.

The ground investigation results shows, the road in between Vartalok and Pragya society of sector 4 (figure 8) of Vasundra has been subside up to 30 feet due to heavy rain fall and water lodging in the area. , ground evidences directly indicates that deformation of road in the form of subsidence in the area of NCR due to water logging by heavy rain fall. The results are showing that the deformation in the some $\mathrm{NC}$

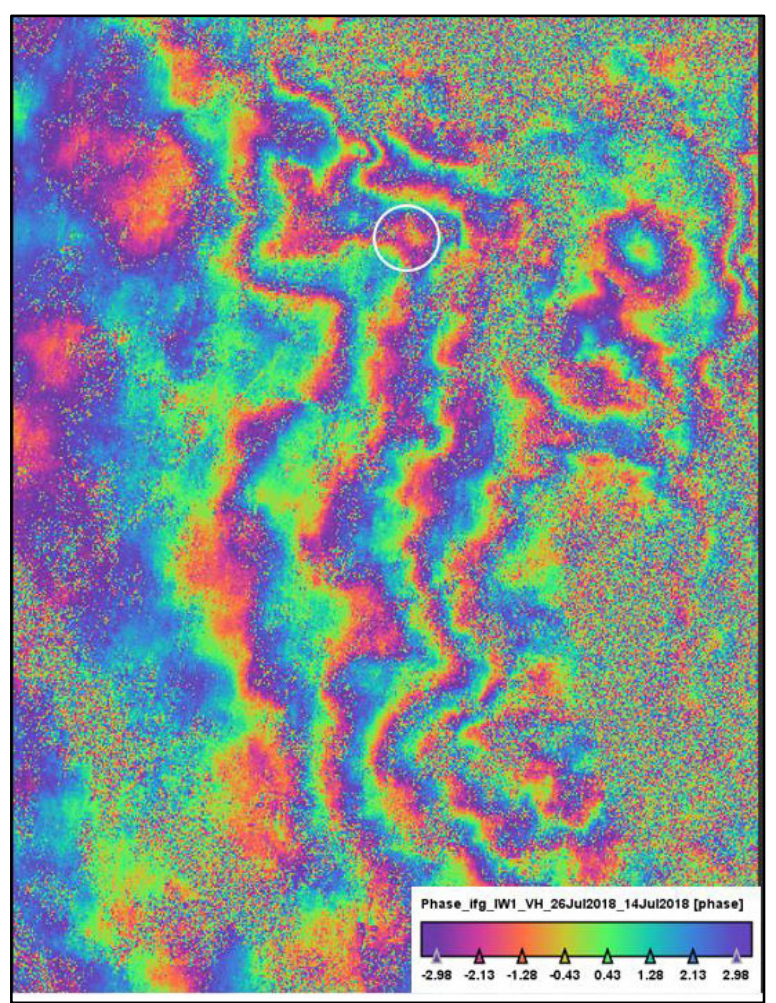

Figure 7 Zoomed view of high deformed area

Region of India has been deformed due to the water logging in the area.

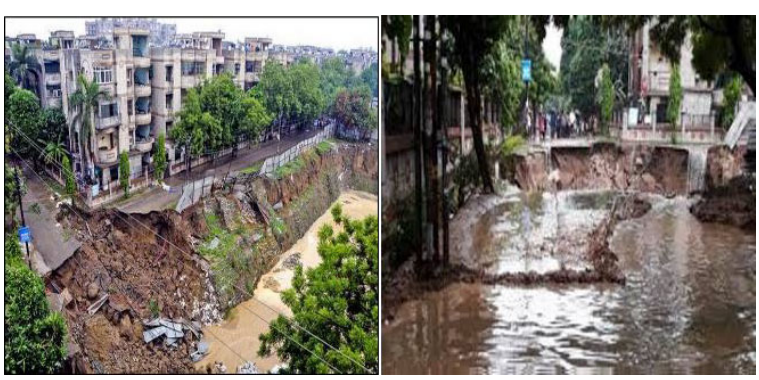

Figure 8 A road subsidence of Vasundra Ghaziabad photographs

\section{CONCLUSION}

The pressure on land for modernization and development increase due to which the deformation of land increases. The results shows, Ghaziabad, Noida, and urban area has high rate of deformation then the part of Delhi and Guru Gram region of NCR using S1, C band SAR data in DInSAR technique. The NCR shows some sign of deformation due by heavy rain fall and water logging in the area. Other factors cannot be ruled out. VV polarization results are good having good results then $\mathrm{VH}$ polarization. The SAR data and DInSAR techniques are competent for urban land deformation.

\section{REFERENCES}

Aydoner, C., D. Maktav, and E. Alparslan. 2004. "Ground Deformation Mapping Using InSAR.” ISPRS Congress Technical Commission I 120-23. Retrieved July 14, 2017 (http://www.isprs.org/proceedings/XXXV/congress/comm1 /papers/23.pdf).

Bhattarai, Richa, Haireti Alifu, Aikebaier Maitiniyazi, and Akihiko Kondoh. 2017. "Detection of Land Subsidence in Kathmandu Valley, Nepal, Using DInSAR Technique." Land 6(2):39. Retrieved August 10, 2017 (http://www.mdpi.com/2073-445X/6/2/39).

Bourbigot, Matthieu, Harald Johnsen, Riccardo Piantanida, Guillaume Hajduch, and Julie Poullaouec. n.d. Sentinel-1 ESA Unclassified-For Official Use Sentinel-1 Product Definition. Retrieved October 1, 2018 (https://sentinel.esa.int/documents/247904/1877131/Sentine 1-1-Product-Definition).

Bürgman, Roland, Paul A. Rosen, and Eric J. Fielding. 2000. "Synthetic Aperture Radar Interferometry to Measure Earth's Surface Topography and Its Deformation." Annual Review of Earth and Planetary Science 28:169-209.

Burgmann, Roland, Paul A. Rosen, and Eric J. Fielding. 2000. "Synthetic a Perture R Adar I Nterferometry To Measure Earth'S Surface Topography and Its Deformation." Annu. Rev. Earth Planet. Sci. 28:169-209.

Bürgmann, Roland, Paul A. Rosen, and Eric J. Fielding. 2000. "Synthetic Aperture Radar Interferometry to Measure Earth's Surface Topography and Its Deformation." Annual Review of Earth and Planetary Sciences 28(1):169-209. 
Retrieved

June

14 ,

2017

(http://www.annualreviews.org/doi/10.1146/annurev.earth. 28.1.169)

Caló, Fabiana et al. 2017. "DInSAR-Based Detection of Land Subsidence and Correlation with Groundwater Depletion in Konya Plain, Turkey.” Remote Sensing 9(1).

Cao, Li et al. 2007. "Coal Mine Land Subsidence Monitoring By Using Spaceborne Insar." Archives (495):255-62. Retrieved September $\quad 12, \quad 2017$ (http://www.isprs.org/proceedings/XXXVII/congress/8_pdf 2_WG-VIII-2/15.pdf)

Champati, P. K., Group Head, and Disaster Studies. 2001. "DInSAR Applications for Landslide and Earthquake Hazard Assessment."

Chang, Hsing-Chung Chang Hsing-Chung, Linlin Ge Linlin Ge, and C. Rizos. 2005. "DInSAR for Mine Subsidence Monitoring Using Multi-Source Satellite SAR Images." Proceedings. 2005 IEEE International Geoscience and Remote Sensing Symposium, 2005. IGARSS '05. 3(3):25966.

Ferretti, A., C. Prati, and F. Rocca. n.d. "Analysis of Permanent Scatterers in SAR Interferometry." Pp. 761-63 in IGARSS 2000. IEEE 2000 International Geoscience and Remote Sensing Symposium. Taking the Pulse of the Planet: The Role of Remote Sensing in Managing the Environment. Proceedings (Cat. No.00CH37120), vol. 2. IEEE. Retrieved July 15 2017 (http://ieeexplore.ieee.org/document/861695/)

Ferretti, Alessandro, Claudio Prati, and Fabio Rocca. 2001. "Permanent Scatterers in SAR Interferometry." IEEE Transactions on Geoscience and Remote Sensing 39(1):820.

Fulton, Allan. 2000. "Land Subsidence: What Is It and Important Aspect of Groundwater Management." Retrieved July 6, 2017 (http://www.water.ca.gov/groundwater/docs/WhatIsLandSu bsidence.pdf).

Gabriel, Andrew K., Richard M. Goldstein, and Howard A. Zebker. 1989. "Mapping Small Elevation Changes over Large Areas: Differential Radar Interferometry." Journal of Geophysical Research 94(B7):9183. Retrieved (http://doi.wiley.com/10.1029/JB094iB07p09183).

Geymen, Abdurrahman. 2014. "Digital Elevation Model (DEM) Generation Using the SAR Interferometry Technique." Arabian Journal of Geosciences 7(2):827-37. $\begin{array}{llll}\text { Retrieved July } & 8017\end{array}$ (http://link.springer.com/10.1007/s12517-012-0811-3).

Iglesias, Rubén et al. 2015. "PSI Deformation Map Retrieval by Means of Temporal Sublook Coherence on Reduced Sets of SAR Images." Remote Sensing 7(1):530-63. Retrieved August 3, $2017 \quad$ (http://www.mdpi.com/2072$4292 / 7 / 1 / 530 /)$

Ishwar, S. G. and Dheeraj Kumar. 2017. "Application of DInSAR in Mine Surface Subsidence Monitoring and
Prediction." Current Science 112(1):46-51. Retrieved June 13, 2017 (http://www.currentscience.ac.in/Volumes/112/01/0046.pdf ).

Jiang, Liming, Hui Lin, Jianwei Ma, Bing Kong, and Yao Wang. 2011. "Potential of Small-Baseline SAR Interferometry for Monitoring Land Subsidence Related to Underground Coal Fires: Wuda (Northern China) Case Study." Remote Sensing of Environment 115(2):257-68. Retrieved (http://dx.doi.org/10.1016/j.rse.2010.08.008)

Klees, Roland and Didier Massonnet. 1999. "Deformation Measurements Using SAR Interferometry: Potential and Limitations." 161-62.

Ng, A. H. M., L. Ge, K. Zhang, and X. Li. 2011. "Application of Persistent Scatterer Interferometry for Land Subsidence Monitoring in Sydney, Australia Using ENVISAT ASAR Data." in 34th International Symposium on Remote Sensing of Environment - The GEOSS Era: Towards Operational Environmental Monitoring. Retrieved September 13 , 2017 (http://www.isprs.org/proceedings/2011/ISRSE34/211104015Final00415.pdf).

Otir, Kritof and Marko Komac. 2007. "PSInSAR and DInSAR Methodology Comparison and Their Applicability in the Field of Surface Deformations - A Case of NW Slovenia Primerjava Uporabe Metodologije PSInSAR in DInSAR Za Opazovanje Premikov Povr $\{$ ja - Primer SZ Dela Slovenije." GEOLOGIJA 501:77-96. Retrieved August $\quad 5, \quad 2017 \quad$ (http://www.geologijarevija.si/dokument.aspx?id=347).

Peltier, A. et al. 2010. "PSInSAR as a New Tool to Monitor Pre-Eruptive Volcano Ground Deformation: Validation Using GPS Measurements on Piton de La Fournaise." Geophysical Research Letters 37(12):1-5.

Qiu, Zhiwei, Jianping Yue, Xueqin Wang, and Shun Yue. 2016. "DEFORMATION MONITORING OF LARGE STRUCTURES BY GROUND-BASED SAR INTERFEROMETRY." Ciênc. Geod., Sec. Artigos, Curitiba 22(1):35-53. Retrieved April 3, 2018 (http://www.scielo.br/pdf/bcg/v22n1/1982-2170-bcg-2201-00035.pdf).

Sahu, Poonam and Ritesh D. Lokhande. 2015. "An Investigation of Sinkhole Subsidence and Its Preventive Measures in Underground Coal Mining." Procedia Earth and Planetary Science 11:63-75. Retrieved (http://linkinghub.elsevier.com/retrieve/pii/S187852201500 0600).

Samieie-Esfahany, Sami, Ramon F. Hanssen, Karin Van Thienen-Visser, and Annemarie Muntendam-Bos. 2009. "ON THE EFFECT OF HORIZONTAL DEFORMATION ON INSAR SUBSIDENCE ESTIMATES." Retrieved September 13, 2017 (http://home.utad.pt/ jjsousa/PARTILHA/Fringes2009/pap ers/s12_3esfa.pdf).

Singh, Madan M. 1992. "Mine Subsidence." SME Mining 
The International Archives of the Photogrammetry, Remote Sensing and Spatial Information Sciences, Volume XLII-5, 2018 ISPRS TC V Mid-term Symposium “Geospatial Technology - Pixel to People”, 20-23 November 2018, Dehradun, India

Engineering Handbook 938-971.

States, United. 1991. "Land Subsidence in the United States." $1-6$.

Strozzi, T., U. Wegmuller, L. Tosi, G. Bitelli, and V. Spreckels. 2001. "Land Subsidence Monitoring with Differential SAR Interferometry." Photogrammetric Engineering \& Remote Sensing 67(11):1261-70.

Tomiyasu, Kiyo. 1978. "Tutorial Review of SyntheticAperture Radar (SAR) with Applications to Imaging of the Ocean Surface." Proceedings of the IEEE 66(5):563-83. 